\title{
FRAGMENTARY FOSSILS AND PALEOECOLOGICAL INFERENCE
}

\author{
CUTLER, Alan H.; BEHRENSMEYER, Anna K., CHAPMAN; Ralph E.,
} Department of Paleobiology, MRC NHB 121, National Museum of Natural History, Smithsonian Institution, Washington, D.C. 20560

Vertebrate skeletons in the fossil record are rarely complete, and paleontologists generally must rely on partial skeletons and isolated bones in making paleoecologic inferences. We present data on skeletal completeness in a modern attritional bone assemblage from a semi-arid landscape in Amboseli National Park, Kenya. Taxon, skeletal parts present, and weathering stage were recorded for 2,414 occurrences of bones and partial skeletons on the land surface in 6 habitats. We use these data to address the following questions: 1) What is the frequency distribution of skeletons of varying states of completeness? 2) Given that a bone is found, what is the probability that other bones of the same individual are also present? 3) How accurately do isolated bones and partial skeletons represent the original community?

The general distribution of completeness classes in Amboseli follows a hollow curve: isolated bones are the most common occurrence (30\%), followed by two bones, three, etc. Therefore, chances are approximately $70 \%$ that more than one bone will be present. This result varies with: 1) taxon (e.g. isolated bones make up 50\% of all giraffe occurrences), 2) skeletal element (e.g. scapulae occur as isolated bones more often than skulls or ribs), 3) weathering stage (weathered bones more likely to occur as isolated bones), and 4) habitat (e.g. bones in the open plains habitat are more frequently isolated than those in the swamp).

Not surprisingly, the more fragmentary the occurrences, the more incomplete and biased the picture of the original community. Forty percent of isolated bone occurrences could not be identified to genus ( $22 \%$ were identifiable only to class), whereas only $3 \%$ of partial skeletons were unidentifiable. This is due not only to the greater amount of anatomical information available from multiple bones, but also to the generally poorer condition of isolated bones. For the 11 most abundant largebodied taxa, rank abundance of isolated bones shows no significant correlation with abundance of these taxa based on ecological surveys (Spearman coefficient $=0.41$, not significant at .05). In contrast, rank abundance of partial skeletons (8 or more bones) correlates well (Spearman coefficient $=0.91$, significant at .01 ).

These results, while specific to the site and taxa studied, can be compared with similar examples from the fossil record to evaluate the quality of information likely to be preserved in fragmentary vertebrate assemblages. The poor representation of species abundance by isolated bones indicates that fluvial assemblages composed of transported, isolated bones are of limited value for inferring paleo- species abundance or rank order. The results provide one model for what can be expected under similar taphonomic circumstances, and there is potential for predicting which additional bones are likely to be present given the find of a particular skeletal part. 